\title{
Effect of porosity and carbon composition on pore microstructure of magnesium/carbon nanotube composite foams
}

Qizhen $\mathrm{Li}^{\mathrm{a}, \mathrm{b}, *}$

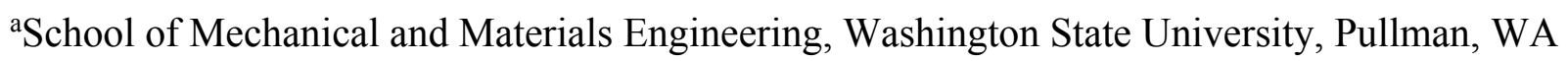
99164

${ }^{b}$ Department of Chemical and Materials Engineering, University of Nevada, Reno, NA 89557

*Corresponding Author: Email: qizhen.li@wsu.edu; Phone: 1-509-335-7437

Abstract: Three-dimensional (3D) pore microstructure was investigated for six types of carbon nanotube $(\mathrm{CNT})$ reinforced porous magnesium $(\mathrm{Mg})$ composite foams with various porosities (i.e. $29 \%, 39 \%$, and $49 \%)$ and compositions $(0.05 w t \% C N T$ and $1 w t \% C N T)$ using the nondestructive x-ray micro-computed tomography technique. The data were analyzed to explore the effect of overall porosity and carbon composition on $3 \mathrm{D}$ pore microstructure such as the number of large pores, pore connectivity, pore size, pore size distribution, pore shape distribution, and specific surface area. The increase of overall porosity resulted in more large and connected pores, and a larger specific surface area. For all studied composite foams, pore size varies in the range of several microns to hundreds of microns; and over $80 \%$ of the pores have the aspect ratio $\leq 2$. The pores with the smallest and biggest sizes occupy only very low volume fractions. The volume fractions for pores with a size $\geq 40 \mu \mathrm{m}$ (i.e. the average size of raw $\mathrm{Mg}$ powders) increases from almost $40 \%$ to about $50 \%$ and then to almost $80 \%$ when the overall porosity increases from $29 \%$ to $39 \%$ and then to $49 \%$. Additionally, the variation of CNT concentration only slightly affects the pore microstructure. 
Keywords: porous magnesium composite, carbon nanotubes, porosity, x-ray micro-computed tomography

\section{Introduction}

Porous Mg-based composite foams are highly appealing for a broad range of structural, hydrogen storage, and bio-implanting applications [1-4]. It is critical to study their 3D pore microstructure since the microstructure information is pivotal for the understanding of properties and the realization of their practical applications in various components. Although some articles reported the microstructure of porous Mg-based materials (e.g. [6-10]), these efforts were mainly devoted to obtain two-dimensional (2D) microstructure images. Recently, the author reported 3D porous structure of one $\mathrm{Mg}$ composite foam with $0.05 \mathrm{wt} \% \mathrm{CNT}$ and $\sim 48.5 \%$ porosity [11]. However, there is no existing knowledge about the effect of porosity and carbon composition on the 3D pore microstructure features of porous $\mathrm{Mg} / \mathrm{CNT}$ composite foams. Therefore, this work employed the non-destructive Micro-CT technique $[12,13]$ to investigate the microstructure details of six types of $\mathrm{Mg} / \mathrm{CNT}$ composite foams and the microstructure variation with the changes of carbon composition and porosity.

\section{Experimental}

Six types of CNT reinforced $\mathrm{Mg}$ composite foams were examined through a high resolution Xradia microxct scanner at the High-Resolution X-ray Computed Tomography (micro-CT) Facility at the University of Texas at Austin. This micro-CT system has a Hamamatsu x-ray source with the energy capability of $40 \sim 150 \mathrm{kV}$ and the spatial resolution ranging from $\sim 30 \mu \mathrm{m}$ to less than $1 \mu \mathrm{m}$ [14]. The foam samples were produced through powder metallurgical processing. Pure $\mathrm{Mg}$ powders, CNTs, and carbamide $\left(\mathrm{CO}\left(\mathrm{NH}_{2}\right)_{2}\right)$ were first mixed 
using ball milling to form a homogeneous mixture. Next, the mixture was pressed into a pellet mold under a pressure of about $120 \mathrm{MPa}$ to produce green compacts. Lastly, the pressed green compacts were sintered to form the final products through heating at $250^{\circ} \mathrm{C}$ for 4 hours and $630^{\circ} \mathrm{C}$ for 2 hours. Pure Mg powders have a powder size on the order of $40 \mu \mathrm{m}$. These composite foams are denoted as $\mathrm{MgC}_{\mathrm{i}}-\mathrm{P}_{\mathrm{j}}$, where $\mathrm{C}, \mathrm{P}$, $\mathrm{i}$, and $\mathrm{j}$ represent $\mathrm{CNT}$, pore, the weight percentage of $\mathrm{CNT}$, and the volume fraction of pores (i.e. overall porosity) respectively. In this study, $\mathrm{i}=0.05$ and $1, \mathrm{j}=29,39$ and 49. The six types of samples are $\mathrm{MgC}_{0.05}-\mathrm{P}_{29}, \mathrm{MgC}_{0.05}-\mathrm{P}_{39}, \mathrm{MgC}_{0.05}-\mathrm{P}_{49}$, $\mathrm{MgC}_{1}-\mathrm{P}_{29}, \mathrm{MgC}_{1}-\mathrm{P}_{39}$ and $\mathrm{MgC}_{1}-\mathrm{P}_{49}$. For each type of sample, a cylindrical region with a diameter of $\sim 2.40 \mathrm{~mm}$ and a height of $\sim 1.75 \mathrm{~mm}$ was scanned to obtain a series of 2D crosssection images with a spatial resolution of $2.4 \mu \mathrm{m}$. These 2D images were then processed, reconstructed, and analyzed using ImageJ [15] to explore the influence of porosity and composition on the 3D pore microstructure.

\section{Results and discussions}

Fig. 1(a-f) reports a representative 2D x-ray image of a cross section for each of the six types of samples. The white region represents the $\mathrm{Mg}$ composite (either $\mathrm{MgC}_{0.05}$ or $\mathrm{MgC}_{1}$ ), and the black region represents the pores. The images show that the pores distributed all across the samples and there are no preferred locations for them. The pore pointed by a blue arrow in Fig. 1(a) has a diameter of $\sim 54 \mu \mathrm{m}$ and an area of $\sim 2290 \mu \mathrm{m}^{2}$, and a pore is designated here as large pore if this pore has an equivalent diameter $\geq 54 \mu \mathrm{m}$. When the CNT concentration $\mathrm{i}$ is fixed at either 0.05 or 1 , the increase of overall porosity results in an increased number of large pores. Among the six types of samples, $\mathrm{MgC}_{0.05}-\mathrm{P}_{29}$ (Fig. 1(a)) and $\mathrm{MgC}_{1}-\mathrm{P}_{29}$ (Fig. 1(b)) have the lowest number of large pores, while $\mathrm{MgC}_{0.05}-\mathrm{P}_{49}$ (Fig. 1(e)) and $\mathrm{MgC}_{1}-\mathrm{P}_{49}$ (Fig. 1(f)) have the 
highest number of large pores. When the overall porosity $\mathrm{j}$ is fixed at 29,39 or 49 , the change of CNT concentration has almost no effect on the number of large pores. For all samples, the pore size varies in a wide range and the pore shape is irregular.

Based on the data from the Micro-CT observation, the local porosities at different cylindrical sample heights were extracted and reported in Fig. 2. The local porosity along the cylindrical height direction of the samples fluctuates between $\sim 28 \%$ and $\sim 30 \%$ for $\mathrm{MgC}_{0.05}-\mathrm{P}_{29}$ and $\mathrm{MgC}_{1}-\mathrm{P}_{29}$, between $\sim 37 \%$ and $\sim 41 \%$ for $\mathrm{MgC}_{0.05}-\mathrm{P}_{39}$ and $\mathrm{MgC}_{1}-\mathrm{P}_{39}$, and between $\sim 46.5 \%$ and $\sim 51.5 \%$ for $\mathrm{MgC}_{0.05}-\mathrm{P}_{49}$ and $\mathrm{MgC}_{1}-\mathrm{P}_{49}$. For both $\mathrm{CNT}$ concentrations, the absolute value of the fluctuation amplitude from the overall porosity increases from $1 \%$ to $2 \%$ and then to $2.5 \%$ when the overall porosity increases from $29 \%$ to $39 \%$ and then to $49 \%$. These fluctuation amplitudes are very small compared with the overall porosities for all six composite foams. Thus, the porosity fluctuation along the height direction is low, and it is reasonable to regard that all samples possess uniform porosity. 

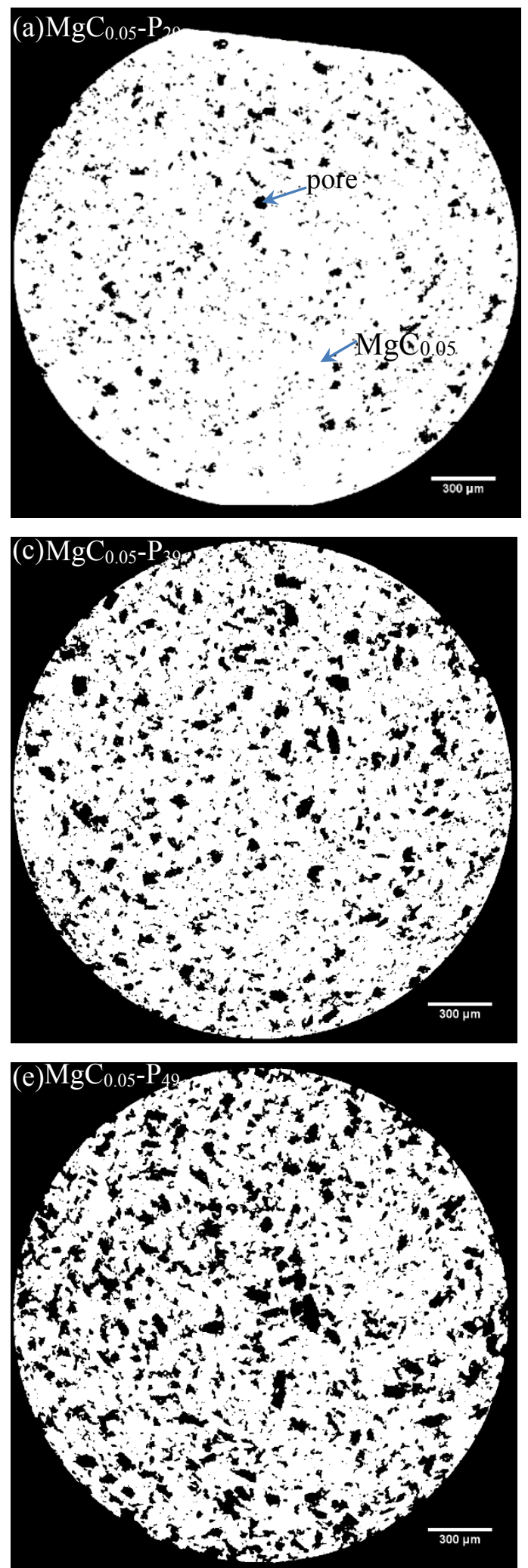
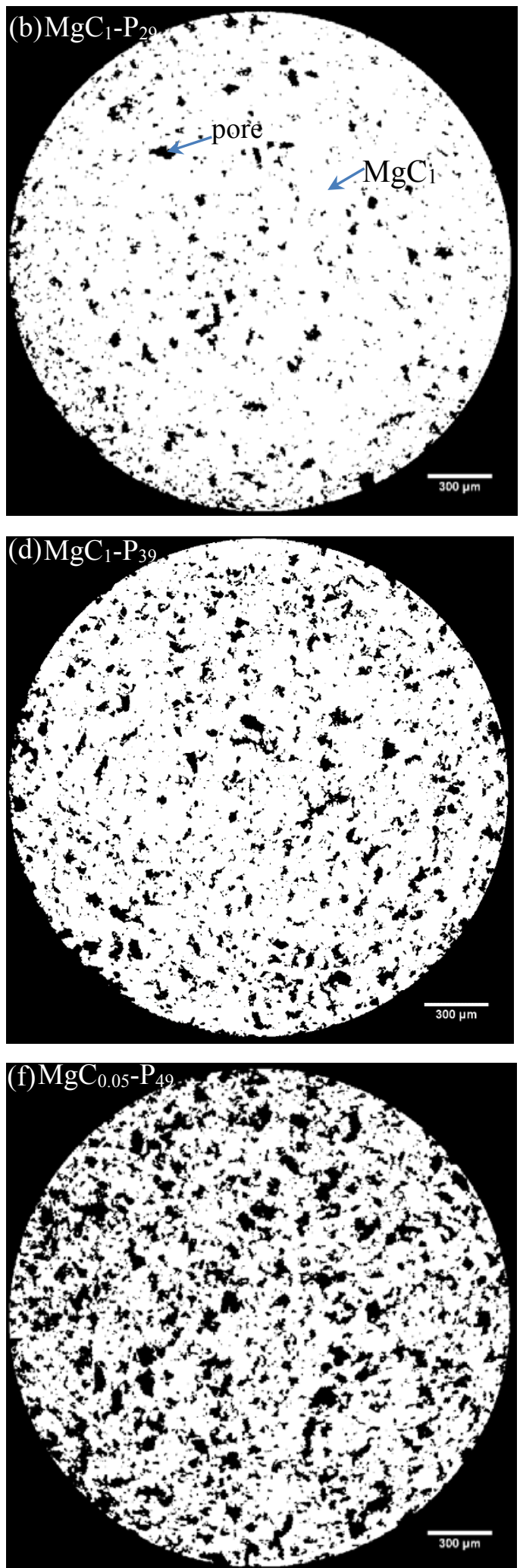

Fig. 1. Representative two-dimensional x-ray images for the six types of porous magnesium composites: (a) $\mathrm{MgC}_{0.05}-\mathrm{P}_{29}$, (b) $\mathrm{MgC}_{1}-\mathrm{P}_{29}$, (c) $\mathrm{MgC}_{0.05}-\mathrm{P}_{39}$, (d) $\mathrm{MgC}_{1}-\mathrm{P}_{39}$, (e) $\mathrm{MgC}_{0.05}-\mathrm{P}_{49}$, and (f) $\mathrm{MgC}_{1}-\mathrm{P}_{49}$. 


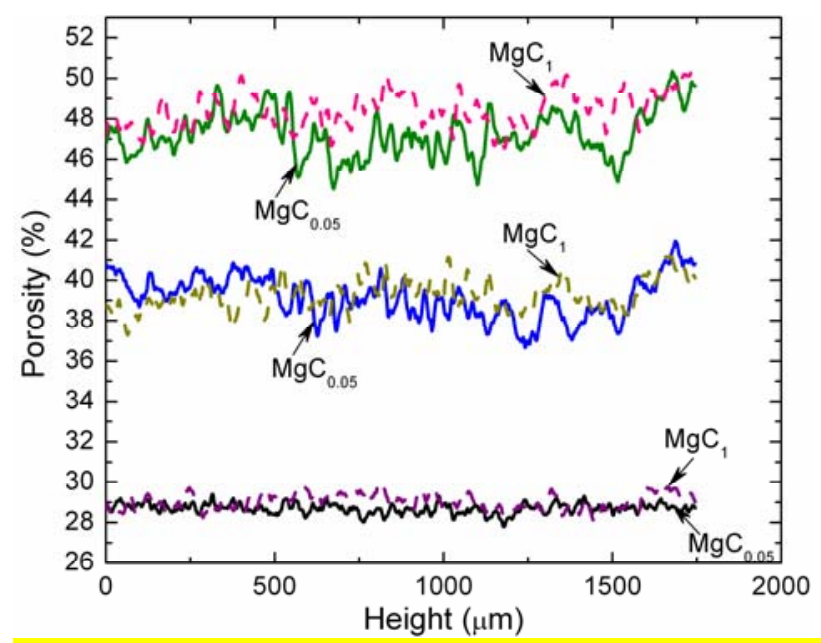

Fig. 2. Local porosity along the cylindrical height of the six samples.

An isometric view was constructed from three orthogonal images for each type of composite foam and was shown in Fig. 3 and 4. The OZ direction is the cylindrical axis along the height direction of the samples. The OX and OY directions are perpendicular to each other and in a plane that is perpendicular to the $\mathrm{OZ}$ direction. Each isometric view displays the pore distributions in one OXY plane, one OYZ plane, and one OXZ plane. For each type of composite foam, the OXY plane is the bottom plane of the cylindrical sample, and the OYZ and OXZ planes are two perpendicular planes containing the center points of all $2 \mathrm{D}$ cross sections that are parallel to the bottom plane. In each plane, the black area is the $\mathrm{Mg}$ composite $\left(\mathrm{MgC}_{0.05}\right.$ and $\mathrm{MgC}_{1}$ ) and the green colored area is the pore space. The OYZ and OXZ planes in Fig. 3 and 4 indicate that they have the similar pore distribution as the OXY plane. This indicates that there is no preferred orientation for the pore distribution and pores are homogeneously located in the whole sample for each type of composite foam.

3D microstructure images for the six types of samples were reconstructed through ImageJ and reported in Fig. 3 (for $\mathrm{MgC}_{0.05}-\mathrm{P}_{29}, \mathrm{MgC}_{0.05}-\mathrm{P}_{39}$, and $\mathrm{MgC}_{0.05}-\mathrm{P}_{49}$ ) and Fig. 4 (for $\mathrm{MgC}_{1}-\mathrm{P}_{29}$, $\mathrm{MgC}_{1}-\mathrm{P}_{39}$, and $\left.\mathrm{MgC}_{1}-\mathrm{P}_{49}\right)$. For all six types of composite foams, the green colored 
volume/particles represents the pores and the open white volume represents $\mathrm{Mg}$ composite as shown by the arrows in Fig. 3(a) and 4(a). There are many isolated/unconnected green particles (i.e. pores) in $\mathrm{MgC}_{0.05}-\mathrm{P}_{29}$ (Fig. 3(a)) and $\mathrm{MgC}_{1}-\mathrm{P}_{29}$ (Fig. 4(a)). With the increase of the overall porosity to $39 \%$, a lot more pores are connected as shown in Fig. 3(c) for $\mathrm{MgC}_{0.05}-\mathrm{P}_{39}$ and Fig. 4(c) for $\mathrm{MgC}_{1}-\mathrm{P}_{39}$. With the further increase of the overall porosity to $49 \%$, most pores are connected as shown in Fig. 3(e) for $\mathrm{MgC}_{0.05}-\mathrm{P}_{49}$ and Fig. 4(e) for $\mathrm{MgC}_{1}-\mathrm{P} 49$.

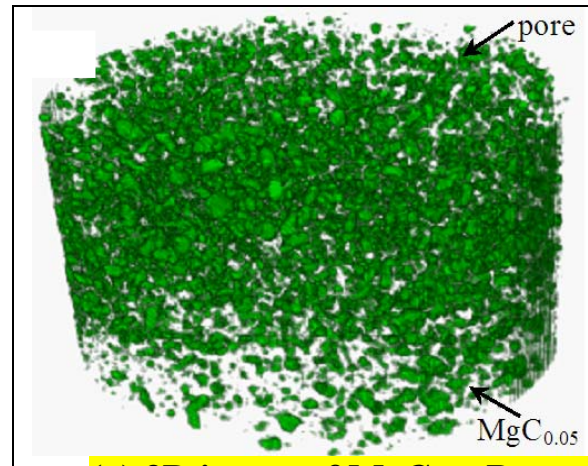

(a) 3D image of $\mathrm{MgC}_{0.05}-\mathrm{P}_{29}$

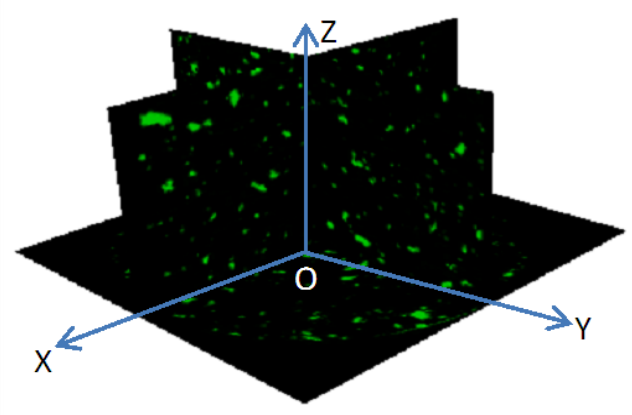

(b) Isometric view of $\mathrm{MgC}_{0.05}-\mathbf{P}_{29}$

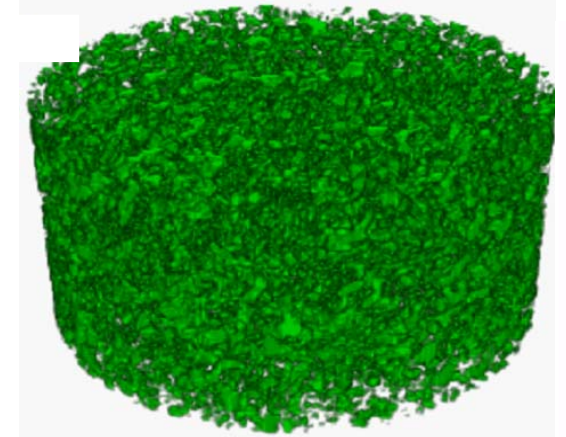

(c) 3D image of $\mathrm{MgC}_{0.05}-\mathrm{P}_{39}$

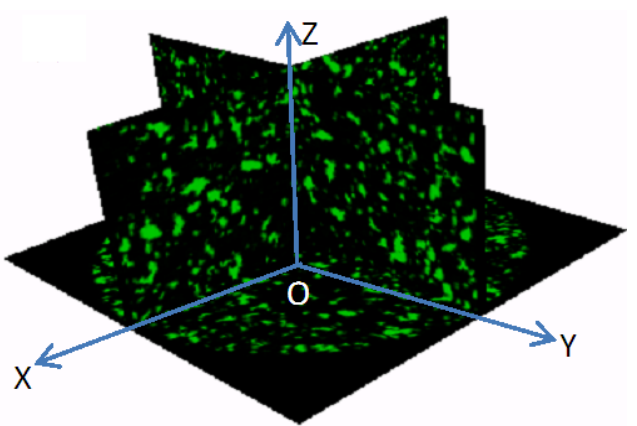

(d) Isometric view of $\mathrm{MgC}_{0.05}-\mathrm{P}_{39}$

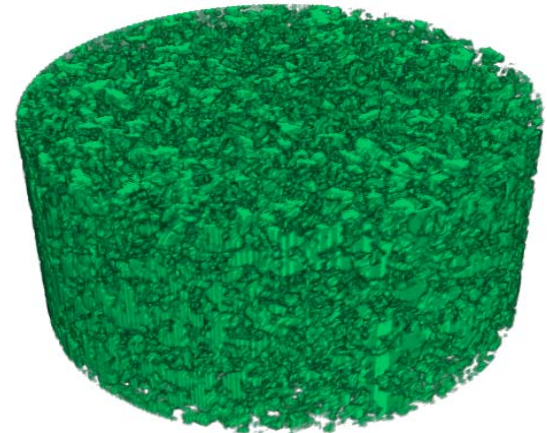

(e) 3D image of $\mathrm{MgC}_{0.05}-\mathrm{P}_{49}$

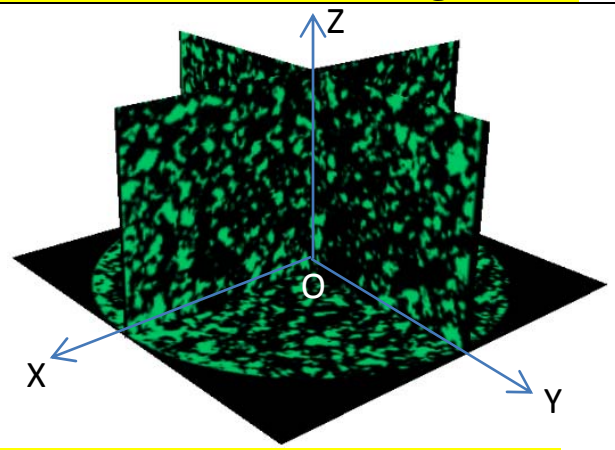

(f) Isometric view of $\mathrm{MgC}_{0.05}-\mathrm{P}_{49}$

Fig. 3. Reconstructed three-dimensional images and isometric views of the three types of porous magnesium composites $\mathrm{MgC}_{0.05}-\mathrm{P}_{29}, \mathrm{MgC}_{0.05}-\mathrm{P}_{39}$, and $\mathrm{MgC}_{0.05}-\mathrm{P}_{49}$. 


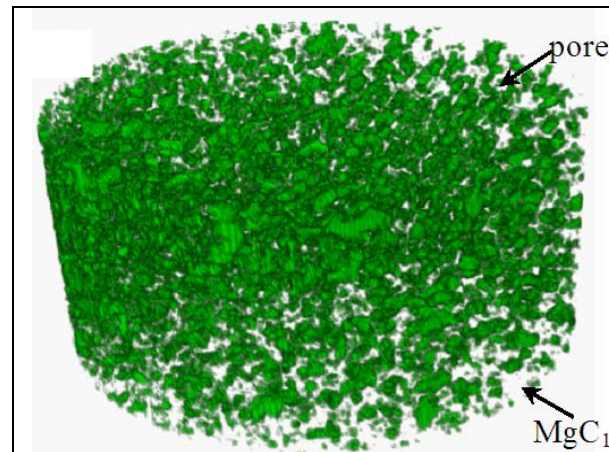

(a) 3D image of $\mathrm{MgC}_{1}-\mathrm{P}_{29}$

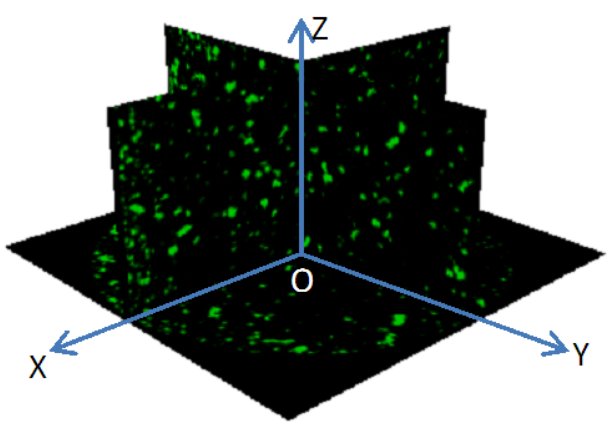

(b) Isometric view of $\mathrm{MgC}_{1}-\mathrm{P}_{29}$

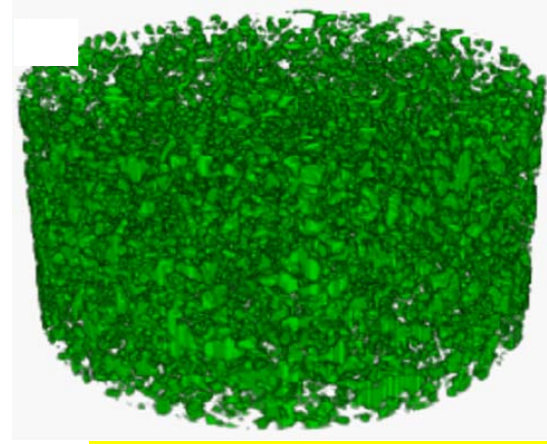

(c) 3D image of $\mathrm{MgC}_{1}-\mathrm{P}_{39}$

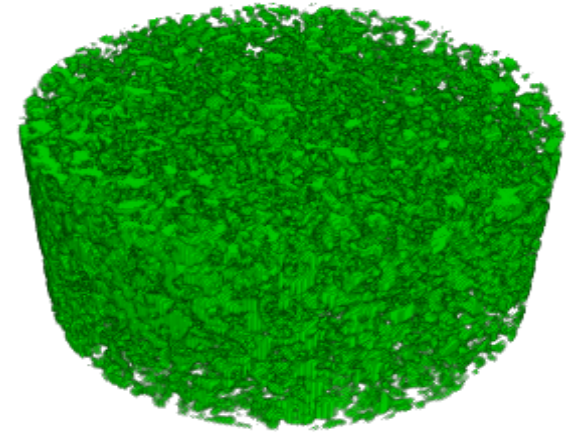

(e) 3D image of $\mathrm{MgC}_{\mathbf{1}}-\mathrm{P}_{\mathbf{4 9}}$

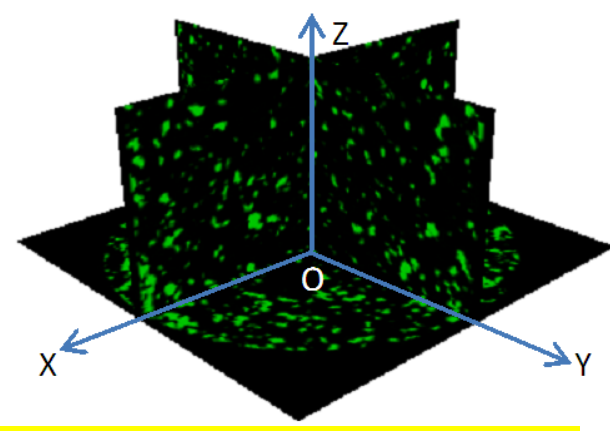

(d) Isometric view of $\mathrm{MgC}_{1}-\mathrm{P}_{39}$

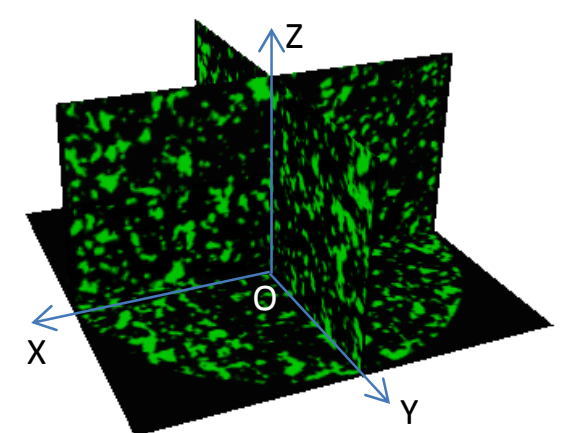

(f) Isometric view of $\mathrm{MgC}_{\mathbf{1}}-\mathrm{P}_{49}$

Fig. 4. Reconstructed three-dimensional images and isometric views of the three types of porous magnesium composites $\mathrm{MgC}_{1}-\mathrm{P}_{29}, \mathrm{MgC}_{1}-\mathrm{P}_{39}$, and $\mathrm{MgC}_{1}-\mathrm{P}_{49}$.

The effect of overall porosity on the pore connectivity can also be displayed by a sequence of 2D images that are parallel to the cylindrical bottom plane as shown in Fig. 5 for $\mathrm{MgC}_{1}-\mathrm{P}_{29}$ and Fig. 6 for $\mathrm{MgC}_{0.05}-\mathrm{P}_{49} . \mathrm{MgC}_{1}-\mathrm{P}_{29}$ is chosen here to represent the low overall porosity case, while the high overall porosity case is represented by $\mathrm{MgC}_{0.05}-\mathrm{P} 49$. Fig. 5(a) to (d) 
provides the cross-section images of Plane 1 to Plane 4 as shown by the outside circular boundaries of these planes in Fig. 5(e). In all 4 planes, a region enclosed by a blue circle is studied. The Pore A1 starts from Plane 1, develops to its largest size in Plane 2, shrinks to a smaller size in Plane 3, and continues shrinking to an even smaller size in Plane 4. The Pore A2 starts in Plane 2 and continues to develop into bigger sizes in Plane 3 and Plane 4. The two pores $\mathrm{A} 1$ and $\mathrm{A} 2$ are discrete and unconnected. Similarly, five cross-section planes of $\mathrm{MgC}_{0.05}-\mathrm{P}_{49}$ are utilized to study the connection among pores. The variation of five pores (i.e. B1, B2, B3, B4, and B5) is followed. B1, B2, and B4 start to connect on Plane ii. B1, B3, and B4 are connected as shown by the images of Plane iii and Plane iv. B1, B4, and B5 are connected as shown by the image of Plane v. Thus, the five pores B1, B2, B3, B4, and B5 are connected. On the images of Plane iii, iv, and v, only a blue circle is drawn to show the studied area and the pores are not labeled to reduce the amount of view blocked by the labeling. These $2 \mathrm{D}$ images illustrate that more pores are connected for the composite foams with higher overall porosity.

If the overall porosity is fixed, the change of carbon composition does not show a visible effect on the connection among pores. White arrows with a diamond head are utilized in Fig. 5(a) and 6(a) to point out the locations of CNTs in $\mathrm{MgC}_{1}-\mathrm{P}_{29}$ and $\mathrm{MgC}_{0.05}-\mathrm{P}_{49} \cdot \mathrm{MgC}_{1}-\mathrm{P}_{29}$ contains a lot more CNTs than $\mathrm{MgC}_{0.05}-\mathrm{P}_{49}$. A typical 2D cross-section image of $\mathrm{MgC}_{1}-\mathrm{P}_{49}$ is reported in Fig. 7, and it indicates that $\mathrm{MgC}_{1}-\mathrm{P}_{49}$ has the same carbon composition as $\mathrm{MgC}_{1}-\mathrm{P}_{29}$ and has the same overall porosity and pore microstructure as $\mathrm{MgC}_{0.05}-\mathrm{P}_{49}$. The set of images from Fig. 5(a) to 5(d) and the set of images from Fig. 6(a) to 5(e) illustrate that CNTs are randomly distributed inside $\mathrm{MgC}_{0.05}$ and $\mathrm{MgC}_{1}$ composites in the whole foam samples for $\mathrm{MgC}_{1}-\mathrm{P}_{29}$ and $\mathrm{MgC}_{0.05}-\mathrm{P}_{49}$, respectively. 

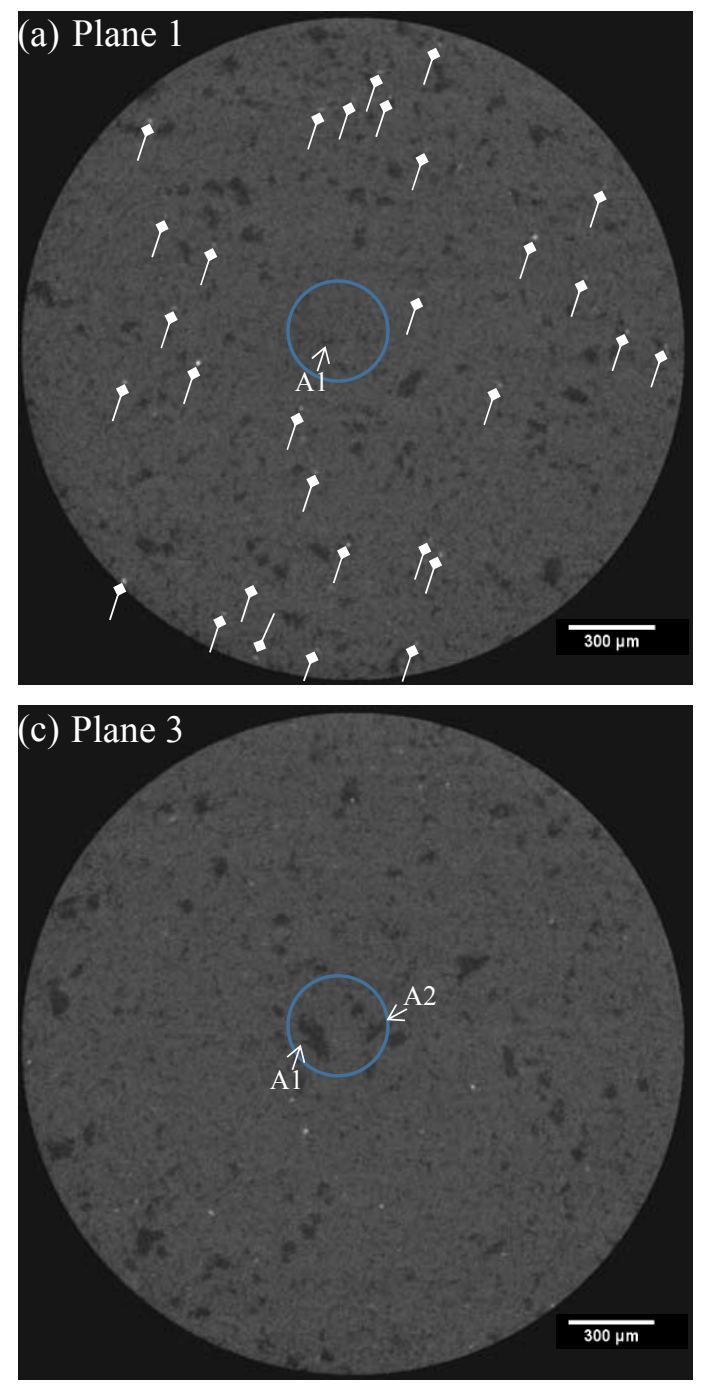

(e)

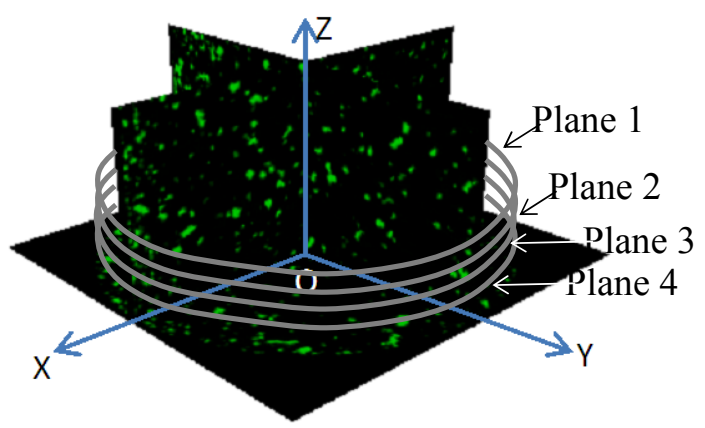

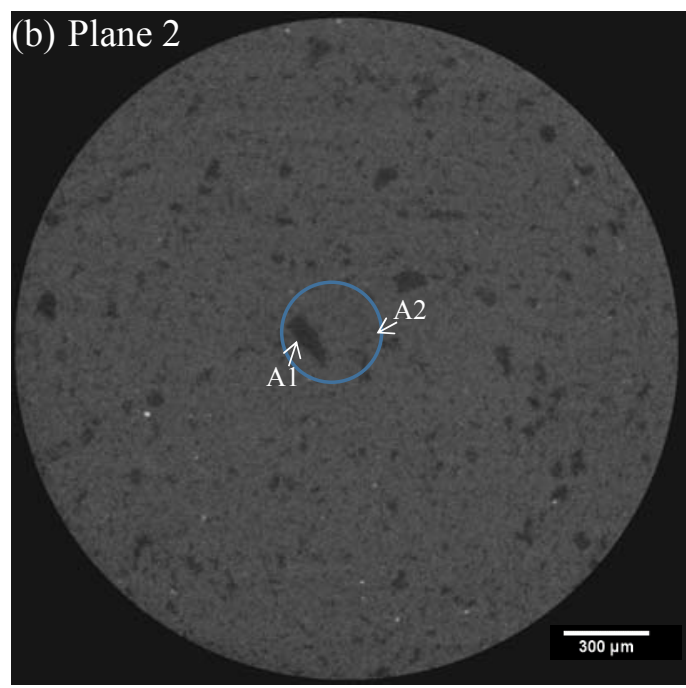

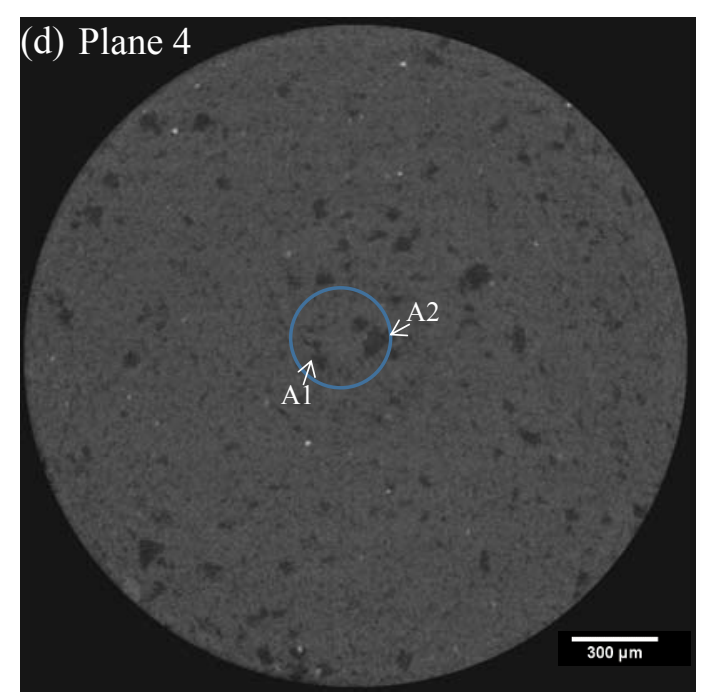

Fig. 5. 2D images of (a) Plane 1, (b) Plane 2, (c) Plane 3, and (d) Plane 4 of $\mathrm{MgC}_{1}-\mathrm{P}_{29}$ that are parallel to the cylindrical bottom plane. (e) Outside boundary sketches of the four planes in (a)(d). 

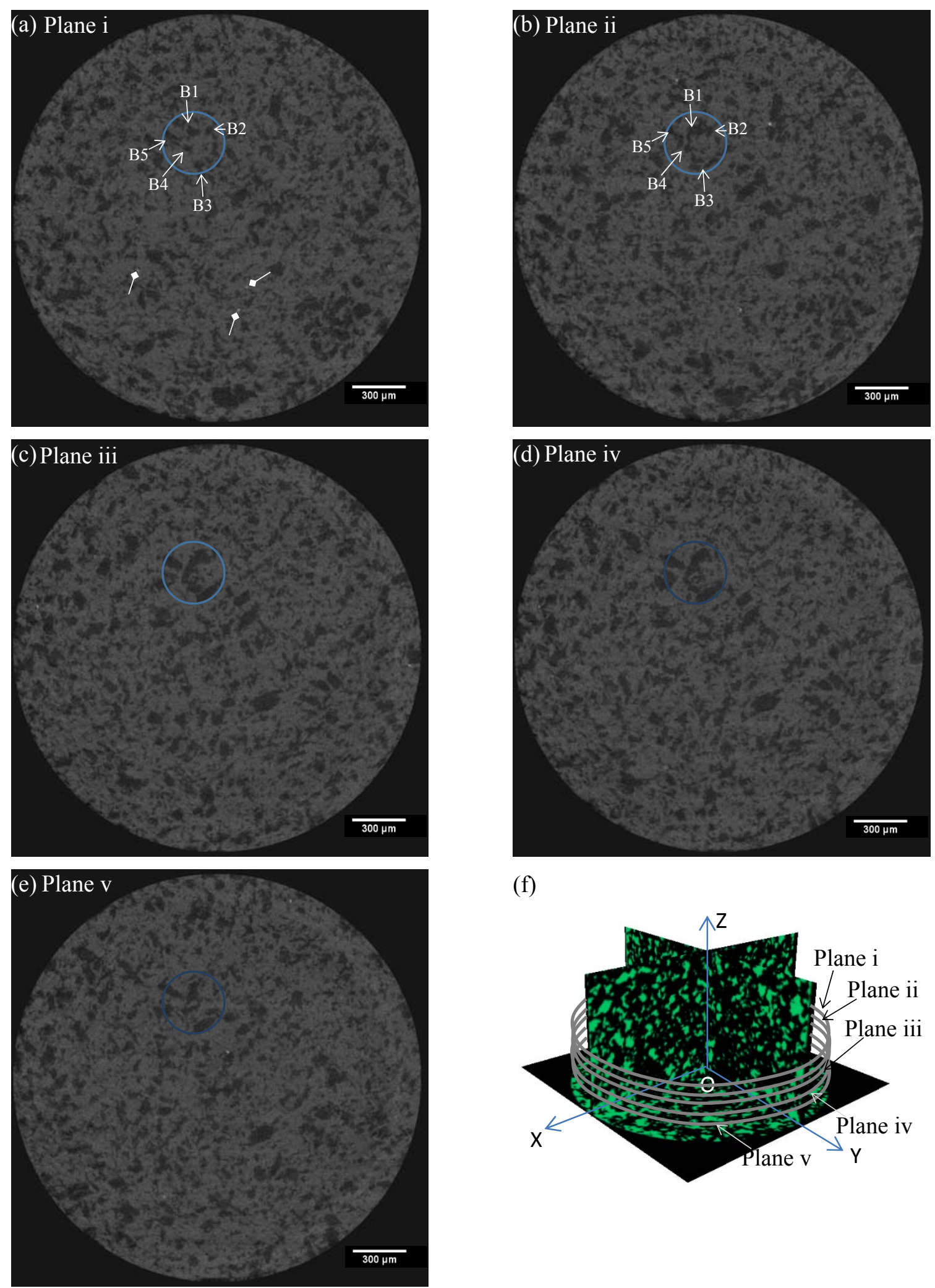

(f)

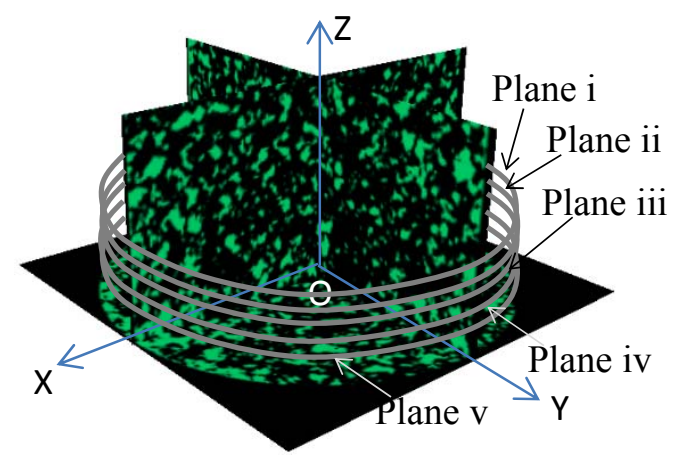

Fig. 6. $2 \mathrm{D}$ images of (a) Plane i, (b) Plane ii, (c) Plane iii, (d) Plane iv, and (e) Plane v of $\mathrm{MgC}_{0.05}-\mathrm{P}_{49}$ that are parallel to the cylindrical bottom plane. (f) Outside boundary sketches of the five planes in (a)-(e). 


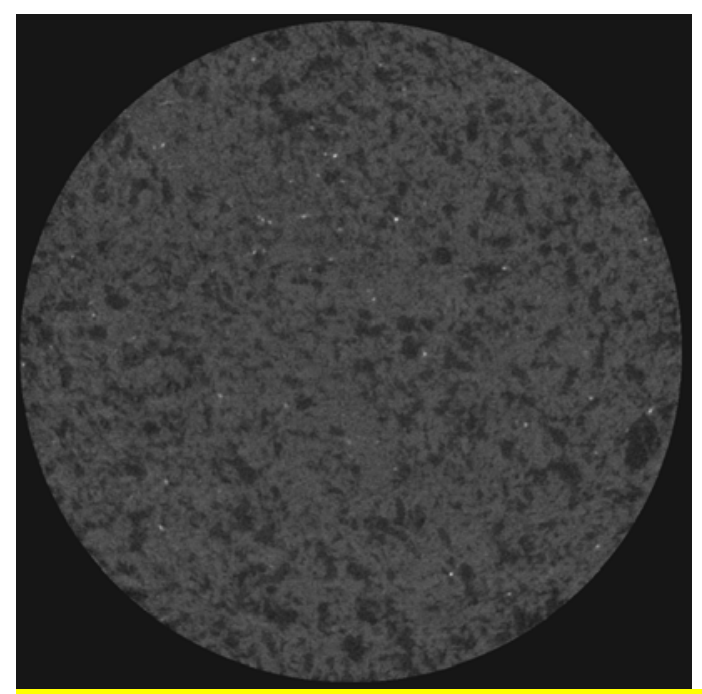

Fig. 7. A typical 2D cross-section image of $\mathrm{MgC}_{1}-\mathrm{P}_{49}$ that is parallel to the cylindrical bottom plane.

In order to perform the quantitative analysis of the pores, each pore was represented by an equivalent circle with the same area as the actual pore. Mathematically, an equivalent radius ( $\mathrm{R}_{\text {equiv. }}$ ) can be computed for an equivalent circle of a pore. An equivalent diameter is referred as the pore size of a pore. The Requiv. was calculated for each pore in the samples. The number of pores with the same Requiv. was obtained and divided by the total number of pores to obtain the occurrence density of this Requiv. and this occurrence density represents the pore size distribution as shown in Fig. 8(a). For all the samples, the minimum equivalent pore radius was about $1.5 \mu \mathrm{m}$. This study also investigated the pore shape distribution since the pores are irregular as shown in Fig. 1. The pores were approximated by ellipses and the pore shape was represented using the aspect ratio (AR) of each ellipse (i.e. AR of an ellipse = the length of major axis/the length of minor axis). The data on the maximum equivalent radius $\left(\mathrm{R}_{\max }\right)$, the maximum aspect ratio $(\mathrm{AR} \max )$, the equivalent radius occurrence density maximum $\left(\rho_{R}^{\max }\right)$, the local maxima of $\mathrm{AR}$ 
occurrence density $\left(\rho_{A R}^{\text {loc.max }}\right)$, external specific surface areas (ESSA), and total specific surface areas (TSSA) of the six types of porous Mg composites are acquired and listed in Table 1.

Table 1. The maximum equivalent radius $\left(R_{\max }\right)$, the maximum aspect ratio $\left(A R_{\max }\right)$, the equivalent radius occurrence density maximum $\left(\rho_{R}^{\max }\right)$, the local maxima of AR occurrence density $\left(\rho_{A R}^{\text {loc. } \max }\right)$, external specific surface areas (ESSA), and total specific surface areas (TSSA) of the four types of porous magnesium composites.

\begin{tabular}{|c|c|c|c|c|c|c|}
\hline Type of sample & 1 & 2 & 3 & 4 & 5 & 6 \\
\hline Composition & \multicolumn{3}{|c|}{$\mathrm{Mg}-0.05 \% \mathrm{C}$} & \multicolumn{3}{|c|}{$\mathrm{Mg}-1 \% \mathrm{C}$} \\
\hline Overall porosity & $\sim 29 \%$ & $\sim 39 \%$ & $\sim 49 \%$ & $\sim 29 \%$ & $\sim 39 \%$ & $\sim 49 \%$ \\
\hline Density, $\mathrm{g} / \mathrm{cm}^{3}$ & $\sim 1.25$ & $\sim 1.06$ & $\sim 0.84$ & $\sim 1.24$ & $\sim 1.06$ & $\sim 0.84$ \\
\hline $\mathrm{R}_{\max }, \mu \mathrm{m}$ & 54 & 85 & 145 & 62 & 68 & 147 \\
\hline$\rho_{R}^{\max }$ at $\mathrm{R}_{\text {equiv. }}=1.5 \mathrm{um}$ & $11.9 \%$ & $10.1 \%$ & $7.65 \%$ & $13.7 \%$ & $10.5 \%$ & $9.54 \%$ \\
\hline$\overline{\mathrm{AR}_{\max }}$ & 7 & 7.6 & 8 & 8 & 8.6 & 7.2 \\
\hline at $\mathrm{AR}=1$ & $21.9 \%$ & $19.5 \%$ & $16.7 \%$ & $23.4 \%$ & $19.8 \%$ & $18.5 \%$ \\
\hline loc. $\max$ at $\mathrm{AR}=1.4$ & $22.7 \%$ & $21.5 \%$ & $20.8 \%$ & $22.8 \%$ & $21.4 \%$ & $21.2 \%$ \\
\hline at $\mathrm{AR}=2$ & $15.3 \%$ & $14.5 \%$ & $13.2 \%$ & $16.1 \%$ & $14.8 \%$ & $14.3 \%$ \\
\hline at $\mathrm{AR}=3$ & $1.76 \%$ & $1.96 \%$ & $1.98 \%$ & $1.97 \%$ & $2.03 \%$ & $2.11 \%$ \\
\hline $\mathrm{ESSA}, \mathrm{mm}^{2} / \mathrm{g}$ & 8096 & 9477 & 11234 & 8086 & 9477 & 11234 \\
\hline $\mathrm{TSSA}, \mathrm{mm}^{2} / \mathrm{g}$ & 62589 & 243193 & 464948 & 81005 & 199963 & 417653 \\
\hline
\end{tabular}

The occurrence density curves of Requiv. for all composite foams in Fig. 8(a) show a consistent decreasing trend with the increase of Requiv. To visualize the pore size distribution 
more clearly, one magnified inset is presented in Fig. 8(a) for the Requiv. from $20 \mu \mathrm{m}$ to $30 \mu \mathrm{m}$. This inset shows that (a) the occurrence densities for the Requiv. of $30 \mu \mathrm{m}$ were less than $0.02 \%$; (b) the curve for $\mathrm{MgC}_{0.05}-\mathrm{P}_{29}$ overlaps with that for $\mathrm{MgC}_{1}-\mathrm{P}_{29}$, and this is true for the pair of $\mathrm{MgC}_{0.05}-\mathrm{P}_{39}$ and $\mathrm{MgC}_{1}-\mathrm{P}_{39}$ and the pair of $\mathrm{MgC}_{0.05}-\mathrm{P}_{49}$ and $\mathrm{MgC}_{1}-\mathrm{P}_{49}$; (c) for each $\mathrm{R}_{\text {equiv. }}$, the composite foam with a higher overall porosity has a higher occurrence density. The volume fraction of each pore size can be obtained. For each composite foam, the occurrence density has a maximum value for the Requiv. of $1.5 \mu \mathrm{m}$ (i.e. a pore size of $3 \mu \mathrm{m}$ ). This pore size is on the order of the spatial resolution of $2.4 \mu \mathrm{m}$ for the Micro-CT. The volume fraction of $3 \mu \mathrm{m}$ sized pores decreases with the increase of overall porosity as shown in Fig. 9(a) for both CNT concentrations, and these volume fractions are lower than $1 \%$ and will not affect the overall porosity and pore microstructure. Meanwhile, the spatial resolution for the Micro-CT was chosen to be able to display the minimum microstructure feature, and the improvement of spatial resolution will not affect the reported results.

$R_{\max }$ in Table 1 shows that its value increases with the increase of overall porosity for both $\mathrm{MgC}_{0.05}$ and $\mathrm{MgC}_{1}$. For each composite foam, the number of the pore with the maximum equivalent radius is one, and the volume fraction of the biggest pore is less than $0.1 \%$ as reported in Fig. 9(b). There is a pore size (i.e. an equivalent diameter) that corresponds to the case that $50 \%$ of the total porous volume are from the pores that are bigger than this size. This pore size is defined as a critical pores size and it increases with the increase of overall porosity as reported in Fig. 10. This critical pore size is about one or two times of the average size of raw Mg powders. Since the raw $\mathrm{Mg}$ powders have an average size of $\sim 40 \mu \mathrm{m}$, it is meaningful to obtain the volume fraction and the number fraction (i.e. occurrence density) of pores with a size $\geq 40 \mu \mathrm{m}$. Fig. 11(a) shows that the volume fraction increases with the increase of overall porosity for the 
pores $\geq 40 \mu \mathrm{m}$, and these pores occupy almost $80 \%$ of the porous volume for the samples with $49 \%$ overall porosity. The number fraction in Fig. 11(b) also increases with the increase of overall porosity, which illustrates quantitatively that the composite foam with a higher overall porosity has more large-sized pores.
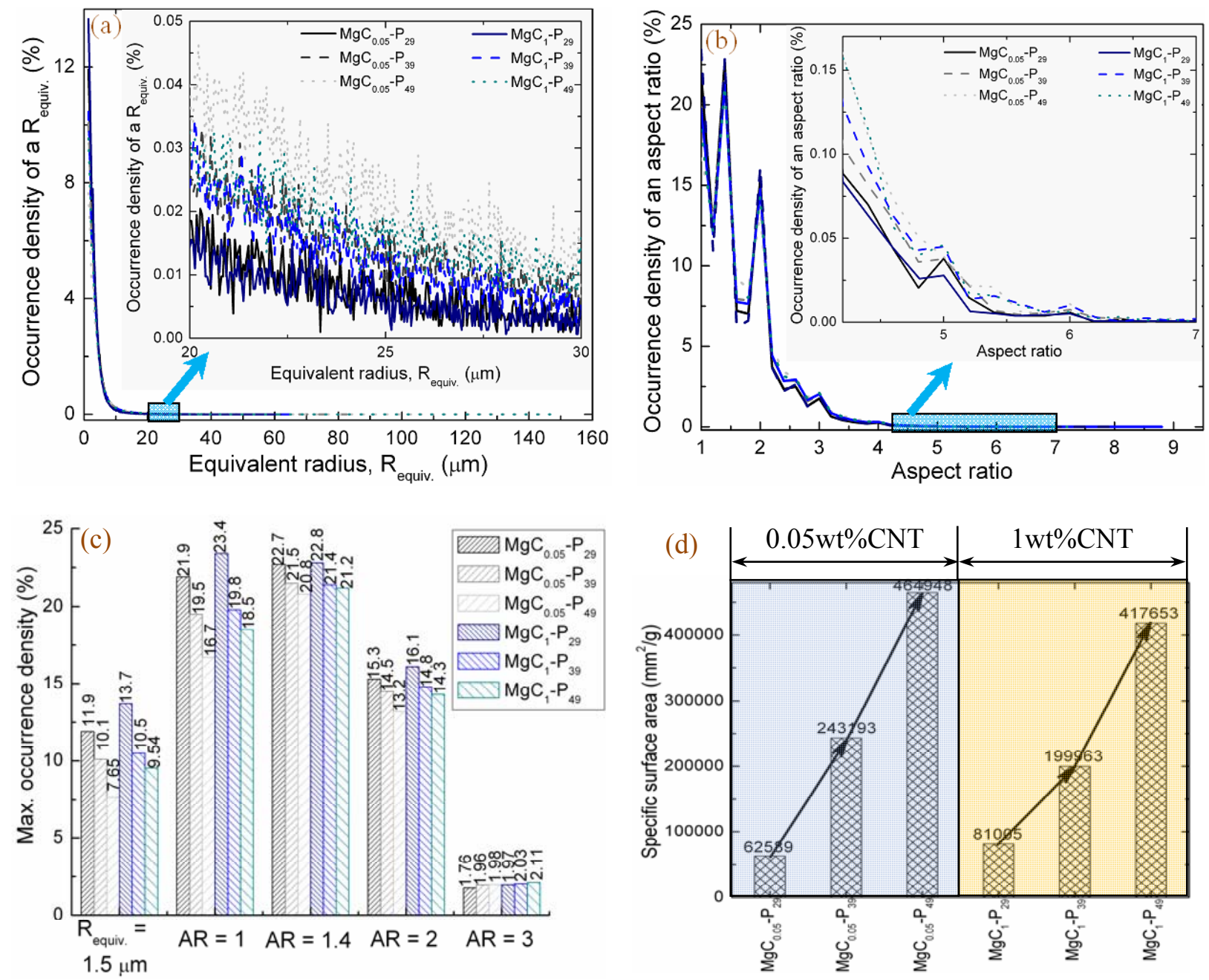

Fig. 8. (a) The occurrence densities of the equivalent radius Requiv, (b) The occurrence densities of the aspect ratio of pores, (c) The maximum occurrence densities at Requiv. $=1.5 \mu \mathrm{m}, \mathrm{AR}=1$, $1.4,2$, and 3 respectively, and (d) Total specific surface areas of the six types of porous magnesium composites. 
Based on a spherical pore approximation, the external specific surface areas (ESSA) and the total specific surface areas (TSSA) of the studied cylindrical samples were computed and reported in Fig. 8(d) and listed in Table 1. TSSA are about 8, 26, 41, 10, 21, and 37 times of their corresponding ESSA for $\mathrm{MgC}_{0.05}-\mathrm{P}_{29}, \mathrm{MgC}_{0.05}-\mathrm{P}_{39}, \mathrm{MgC}_{0.05}-\mathrm{P}_{49}, \mathrm{MgC}_{1}-\mathrm{P}_{29}, \mathrm{MgC}_{1}-\mathrm{P}_{39}$, and $\mathrm{MgC}_{1}-\mathrm{P}_{49}$ respectively. $\mathrm{MgC}_{0.05}-\mathrm{P}_{29}$ and $\mathrm{MgC}_{0.05}-\mathrm{P}_{49}$ have the lowest and highest TSSA respectively. The increase of overall porosity significantly increases the TSSA. For a fixed overall porosity, the change of CNT concentration only slightly affects the TSSA.
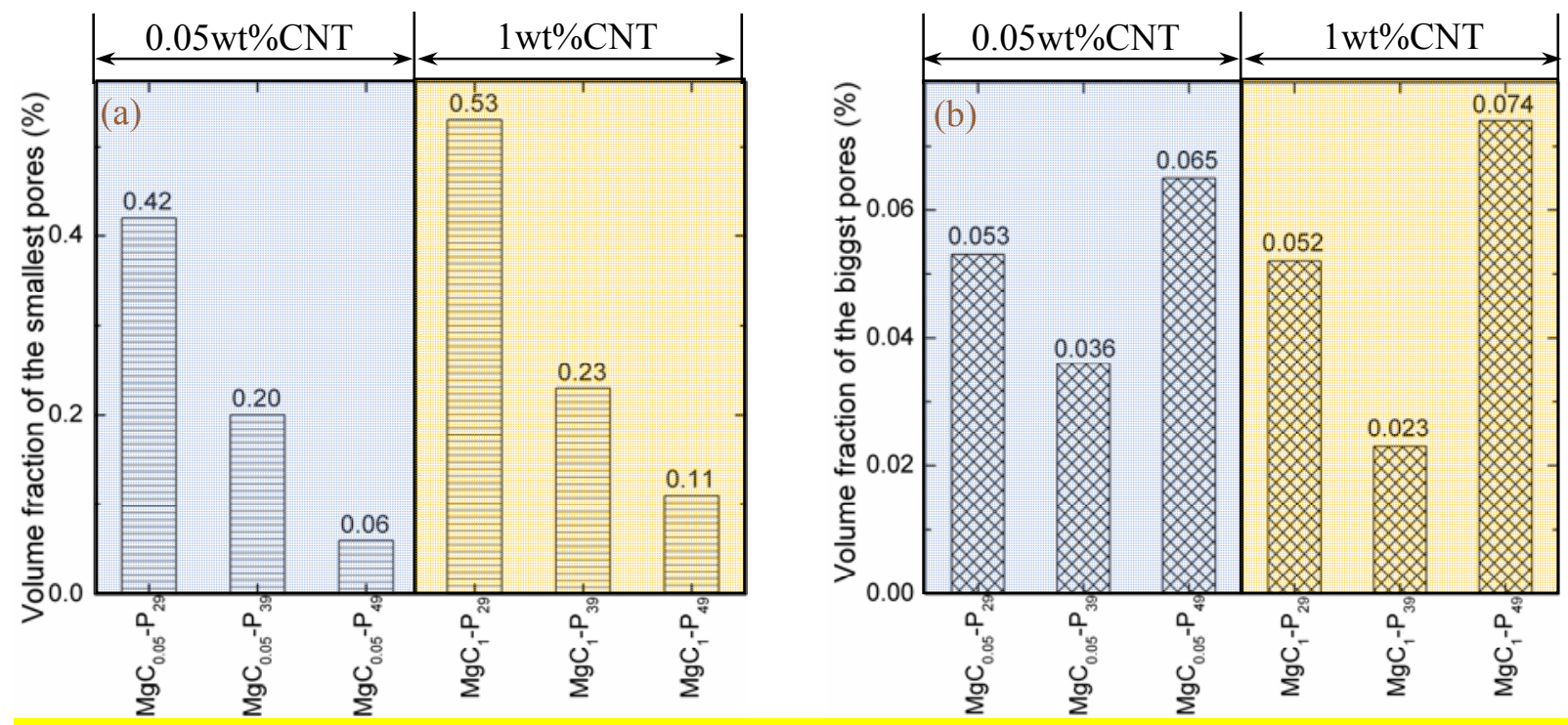

Fig. 9. Volume fractions of (a) the smallest pores and (b) the biggest pores for the six types of porous magnesium composites.

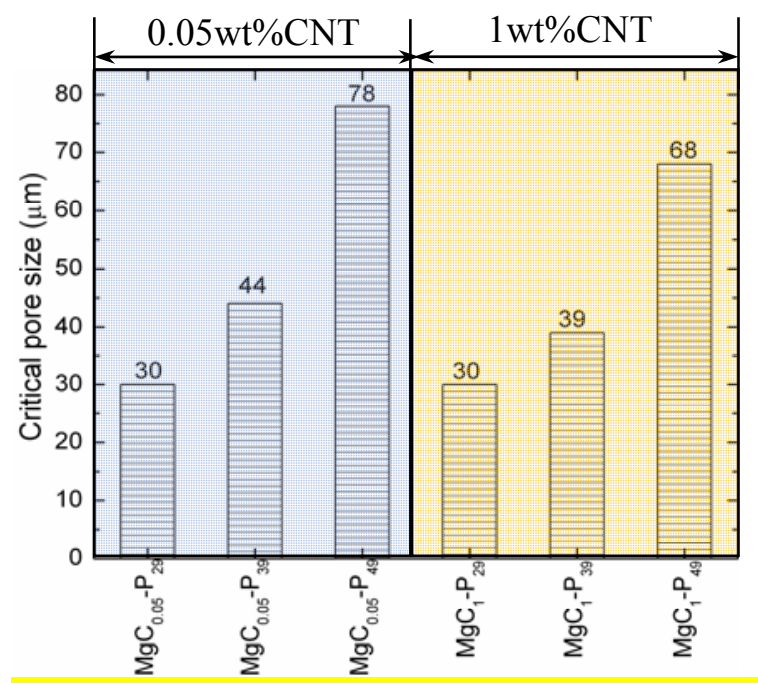

Fig. 10. Critical pore sizes of the six types of porous magnesium composites. 

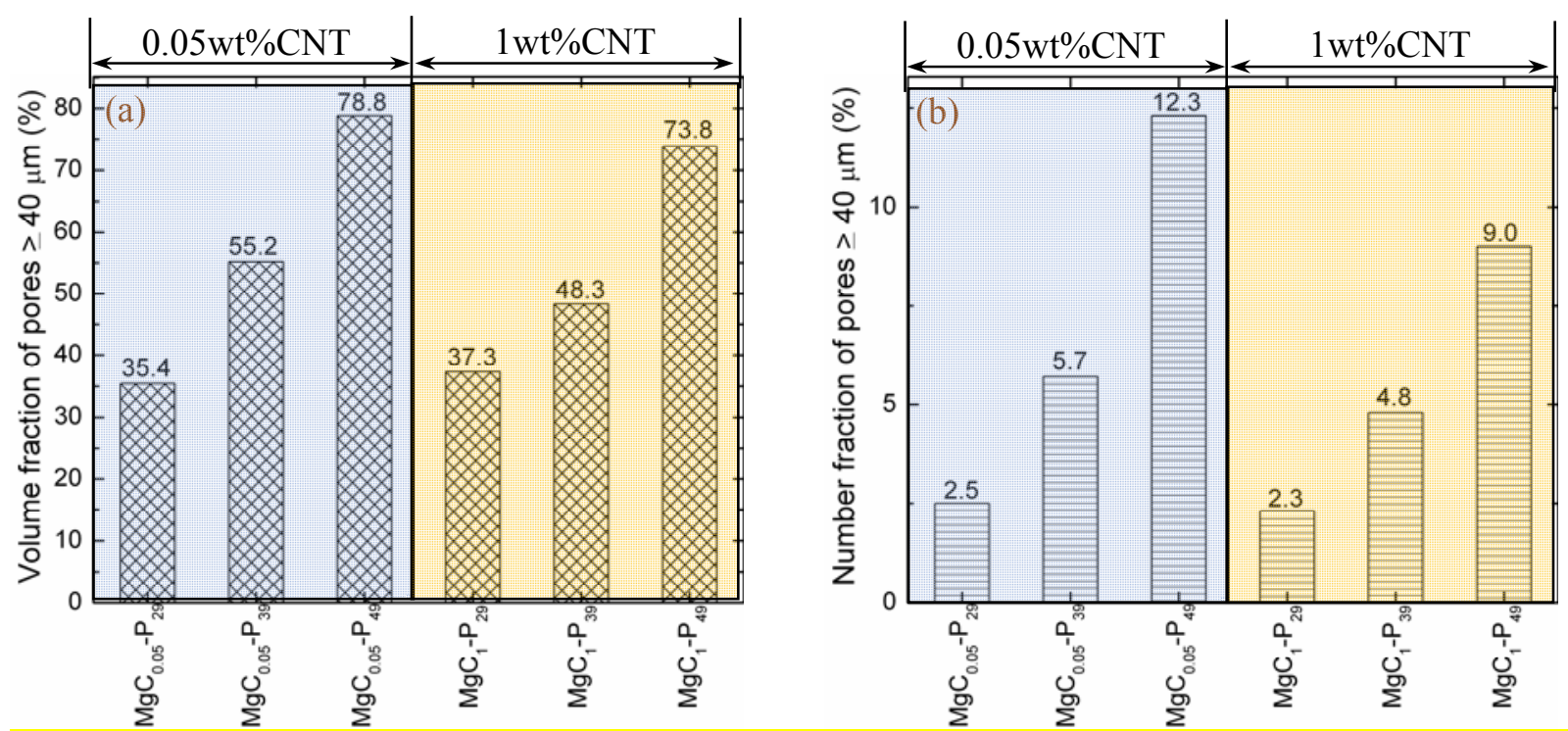

Fig. 11. (a) Volume fractions and (b) number fractions of the pores with a size $\geq 40 \mu \mathrm{m}$ for the six types of porous magnesium composites.

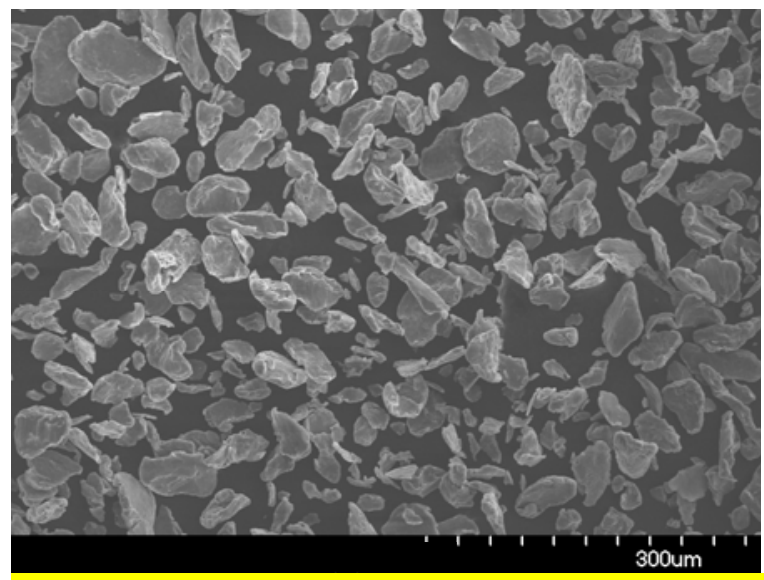

Fig. 12. Scanning electron microsopy image of raw Mg powders.

The occurrence densities of all AR values (i.e. pore shape distributions) were obtained for each type of sample as reported in Fig. 8(b). The lowest AR is 1 . The higher an AR is, the more elongated an ellipse is. One magnified inset is included in Fig. 8(b) for the region with the AR of 4.2 to 7. The overall trend is that the pore AR occurrence density decreases with the increase of AR. The inset also exhibits that this occurrence density is lower than $0.05 \%$ when $\mathrm{AR}$ is higher than 5 . 
When AR is lower than 3.5, there are several local maximum humps for the AR occurrence densities of each sample. The corresponding ARs for these local maxima ( $\left.\rho_{A R}^{\text {loc.max }}\right)$ are 1, 1.4, 2, and 3 as shown in Fig. 8(c). When fixing the overall porosity, the samples with different CNT concentrations have similar $\rho_{A R}^{\text {loc.max }}$ at $\mathrm{AR}=1,1.4,2$, and 3. When fixing the CNT concentration, the samples with different overall porosities have different $\rho_{A R}^{\text {loc.max }}$ at $\mathrm{AR}=$ $1,1.4,2$, and 3 , and the difference decreases to be negligible when the AR increases to 3 . The absolute maximum values $\left(\rho_{A R}^{\text {abs max }}\right)$ of the AR occurrence density are $22.7 \%, 21.5 \%, 20.8 \%$, 23.4\%, 21.4\%, and 21.2\% for $\mathrm{MgC}_{0.05}-\mathrm{P}_{29}, \mathrm{MgC}_{0.05}-\mathrm{P}_{39}, \mathrm{MgC}_{0.05}-\mathrm{P}_{49}, \mathrm{MgC}_{1}-\mathrm{P}_{29}, \mathrm{MgC}_{1}-\mathrm{P}_{39}$, and $\mathrm{MgC}_{1}-\mathrm{P}_{49}$ respectively. $\rho_{A R}^{\text {abs max }}$ occurs at $\mathrm{AR}=1.4$ for $\mathrm{MgC}_{0.05}-\mathrm{P}_{29}, \mathrm{MgC}_{0.05}-\mathrm{P}_{39}, \mathrm{MgC}_{0.05}-\mathrm{P}_{49}$, $\mathrm{MgC}_{1}-\mathrm{P}_{39}$, and $\mathrm{MgC}_{1}-\mathrm{P}_{49}$, while it occurs at $\mathrm{AR}=1$ for $\mathrm{MgC}_{1}-\mathrm{P}_{29}$. Thus, $21 \sim 24 \%$ pores have a shape that is close to circular. The increase of overall porosity reduces the percentage of circular pores, and this may be related to the more connected pores in the samples with higher overall porosity. The percentages for $\mathrm{AR} \leq 3$ and $\mathrm{AR} \leq 2$ are presented in Fig. 13(a) and (b). All samples have over $80 \%$ of pores with $\mathrm{AR} \leq 2$. The high percentages for $\mathrm{AR} \leq 2$ in all composite foams may be related to the raw Mg powders that possess $\mathrm{AR} \leq 2$ as shown in Fig. 12 . 

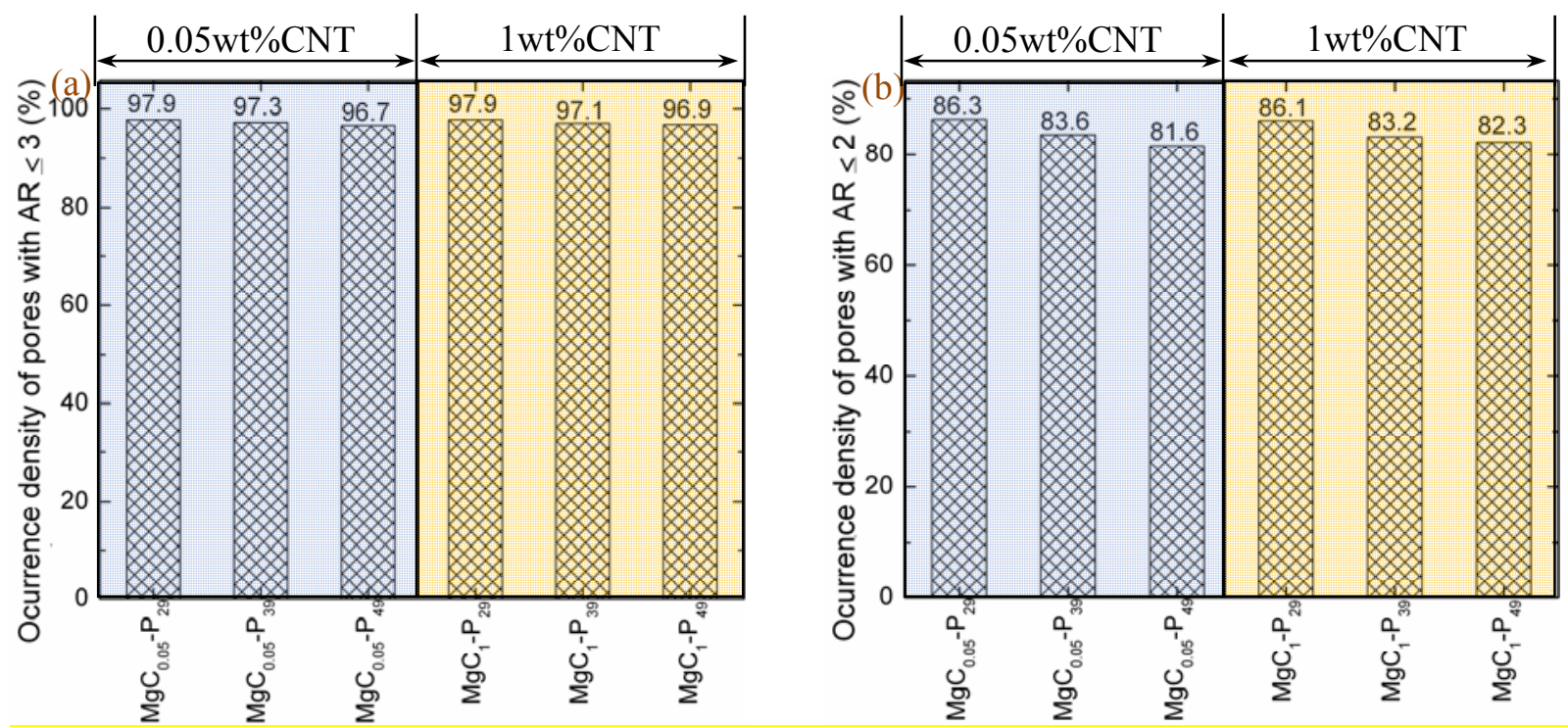

Fig. 13. Occurrence density of pores with (a) $A R \leq 3$ and (b) $A R \leq 2$ for the six types of porous magnesium composites.

\section{Conclusion}

The 3D pore microstructure features was investigated for six types of porous $\mathrm{Mg} / \mathrm{CNT}$ composite foams (i.e. $\mathrm{MgC}_{0.05}-\mathrm{P}_{29}, \mathrm{MgC}_{0.05}-\mathrm{P}_{39}, \mathrm{MgC}_{0.05}-\mathrm{P}_{49}, \mathrm{MgC}_{1}-\mathrm{P}_{29}, \mathrm{MgC}_{1}-\mathrm{P}_{39}$, and $\mathrm{MgC}_{1}$ $\mathrm{P}_{49}$ ). The following conclusion was drawn from this study.

(i) Carbon composition had negligible effect on pore microstructure features (i.e. the number of large pores, the connection among pores, pore size, pore size distribution, pore shape distribution, and total specific surface area).

(ii) Porosity fluctuation: The local porosity fluctuation within a sample becomes larger with the increase of overall porosity. The absolute fluctuation amplitudes are $1 \%$ around overall porosity $29 \%, 2 \%$ around overall porosity $39 \%$, and $2.5 \%$ around overall porosity $49 \%$. These fluctuations are very small comparing to each overall porosity and the porosity can be regarded to be uniform for each sample. The pores distributed uniformly inside each composite foam. 
(iii) Pore size and pore size distribution: The composite foams with higher overall porosity have a higher number of large pores, and more connected pores than the composites with lower overall porosity. The maximum pore size increases with the increase of overall porosity. Pore size varies in the range of several microns to hundreds of microns for all samples. With the increase of overall porosity, pore size varies in a larger range. The pores with the smallest and biggest sizes occupies only very low volume fractions (less than $1 \%$ ). The volume fractions for pores with a size $\geq 40 \mu \mathrm{m}$ (i.e. the average size of raw Mg powders) increases from almost $40 \%$ to about $50 \%$ and then to almost $80 \%$ when the overall porosity increases from $29 \%$ to $39 \%$ and then to $49 \%$.

(iv) Total specific surface area: TSSA increases significantly with the increase of overall porosity. TSSA are about 8, 26, 41, 10,21, and 37 times of their corresponding ESSA for $\mathrm{MgC}_{0.05}-\mathrm{P}_{29}, \mathrm{MgC}_{0.05}-\mathrm{P}_{39}, \mathrm{MgC}_{0.05}-\mathrm{P}_{49}, \mathrm{MgC}_{1}-\mathrm{P}_{29}, \mathrm{MgC}_{1}-\mathrm{P}_{39}$, and $\mathrm{MgC}_{1}-\mathrm{P}_{49}$ respectively.

(v) Pore shape distribution: For each of the studied CNT concentration, the samples with different overall porosities have different local occurrence density maxima at $\mathrm{AR}=1,1.4$, 2, and 3, and the difference in the maxima decreases with the increase of AR. 16.7 23.4\% pores are circular pores for the six composite foams. The increase of overall porosity increases the connection among pores and thus reduces the percentage of circular pores. For all composite foams, over $80 \%$ of the pores have the $\mathrm{AR} \leq 2$, and this may be related to the morphology of raw Mg powders that mostly possess an aspect ratio of $\leq 2$.

\section{Acknowledgments}


The support for the research from the National Science Foundation under Award numbers 1055073 and 1449607 is greatly appreciated.

\section{References}

[1] M.M. Avedesian and H. Baker, Magnesium and Magnesium Alloys, ASM International, Materials Park, OH (1999).

[2] B. Sakintuna, F. Lamari-Darkrim, and M. Hirscher, Metal hydride materials for solid hydrogen storage: A review, Int. J. Hydrogen Energy 32, 1121-40 (2007).

[3] L. Schlapbach and A. Züttel, Hydrogen-storage materials for mobile applications, Nature 414, 353-8 (2001).

[4] R. Zeng, W. Dietzel, F. Witte, N. Hort, and C. Blawert, Progress and Challenge for Magnesium Alloys as Biomaterials, Adv. Eng. Mater. 10, B3-14 (2008).

[5] Y. Yamada, K. Shimojima, Y. Sakaguchi, M. Mabuchi, M. Nakamura, T. Asahina, T. Mukai, H. Kanahashi, and K. Higashi, Compressive properties of open-cellular SG91A $\mathrm{Al}$ and AZ91 Mg, Mat. Sci. Eng. A 272, 455-8 (1999).

[6] S. Ho, C. Ravindrana, and G.D. Hibbard, Magnesium alloy micro-truss materials, Scripta Mater. 62, 21-4 (2010).

[7] C.E. Wen, Y. Yamada, K. Shimojima, Y. Chino, H. Hosokawa, and M. Mabuchi, Compressibility of porous magnesium foam: dependency on porosity and pore size, Mater. Lett. 58, 357-60 (2004).

[8] G. Hao, F. Han, and W. Li, Processing and mechanical properties of magnesium foams, J. Porous Mater. 16, 251-6 (2009). 
[9] H. Cay, H. Xu, and Q.Z. Li, Mechanical Behavior of Porous Magnesium/Alumina Composites with High Strength and Low Density, Mat. Sci. Eng. A 574, 137-42 (2013).

[10] M.H. Kang, H.D. Jung, S.W. Kim, S.M. Lee, H.E. Kim, Y. Estrin, and Y. Koh, Production and bio-corrosion resistance of porous magnesium with hydroxyapatite coating for biomedical applications, Mater. Lett. 108, 122-4 (2013).

[11] Q.Z. Li, Carbon nanotube reinforced porous magnesium composite: 3D nondestructive microstructure characterization using x-ray micro-computed tomography, Mater. Lett. 13, 83-6 (2014).

[12] C.A. Carlsson, Computerized tomography for non-destructive testing of materials and its efficient use, Materials and Design 13, 265-8 (1992).

[13] B.M. Patterson, J.P. Escobedo-Diaz, D. Dennis-Koller, and E. Cerreta, Dimensional quantification of embedded voids or objects in three dimensions using X-ray tomography, Microsc. Microanal. 18, 390-8 (2012).

[14] http://www.ctlab.geo.utexas.edu/labcap/index.php

[15] http://rsbweb.nih.gov/ij/ 


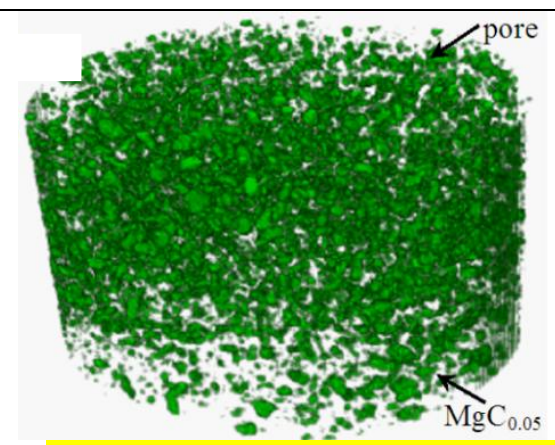

(a) 3D image of $\mathrm{MgC}_{0.05}-\mathrm{P}_{29}$

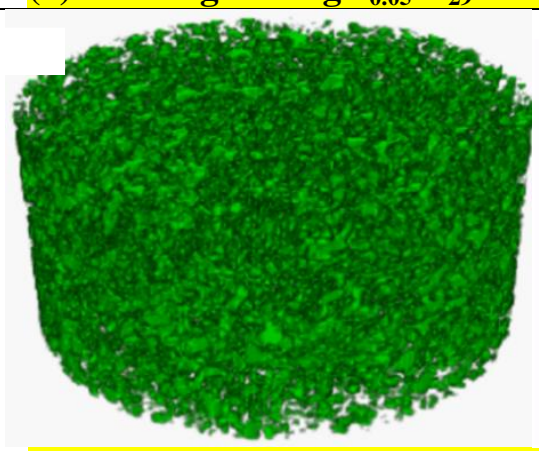

(d) 3D image of $\mathrm{MgC}_{0.05}-\mathrm{P}_{39}$

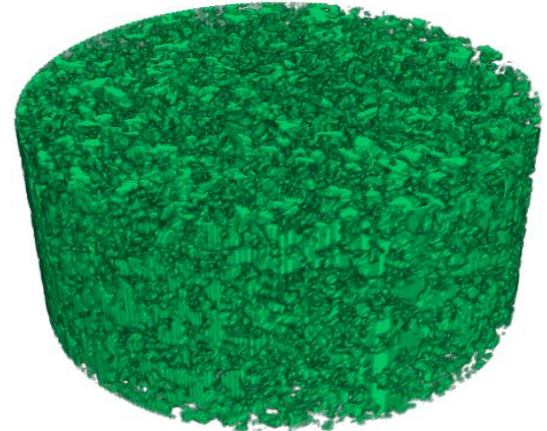

(g) 3D image of $\mathrm{MgC}_{0.05}-\mathrm{P}_{49}$

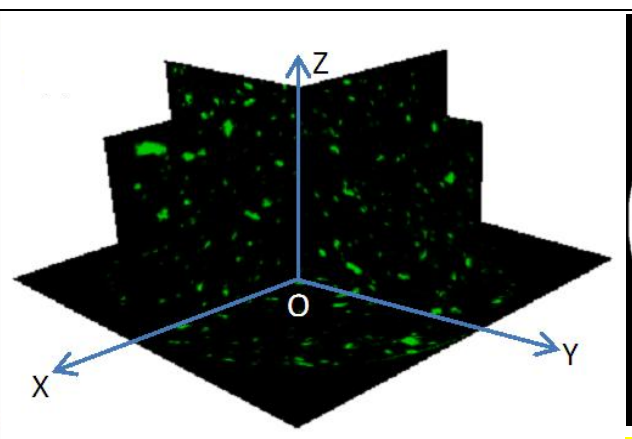

(b) Isometric view of $\mathrm{MgC}_{0.05}-\mathrm{P}_{29}$

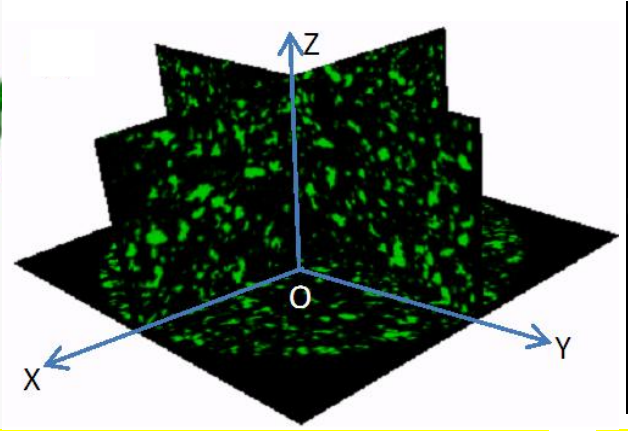

(e) Isometric view of $\mathrm{MgC}_{0.05}-\mathrm{P}_{39}$

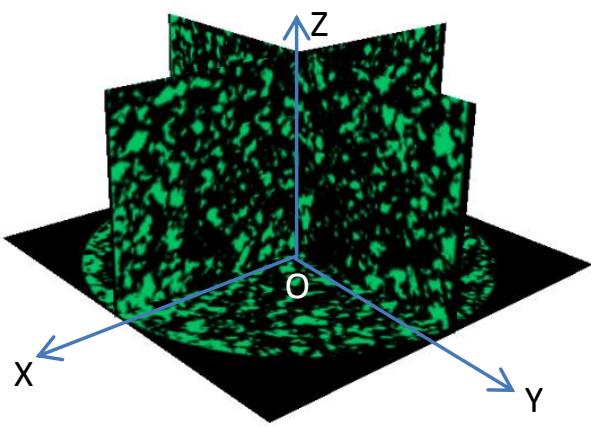

(h) Isometric view of $\mathrm{MgC}_{0.05}-\mathrm{P}_{49}$ (c) 2D image of $\mathrm{MgC}_{0.05}-\mathrm{P}_{29}$

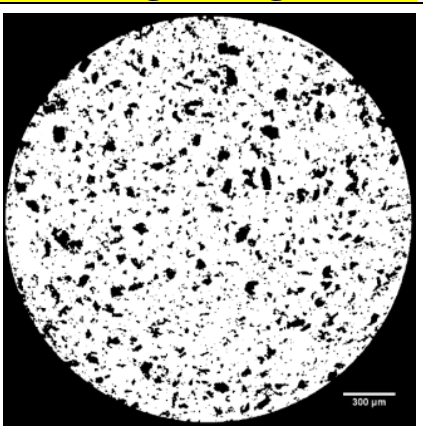

(f) 2D image of $\mathrm{MgC}_{0.05}-\mathrm{P}_{39}$
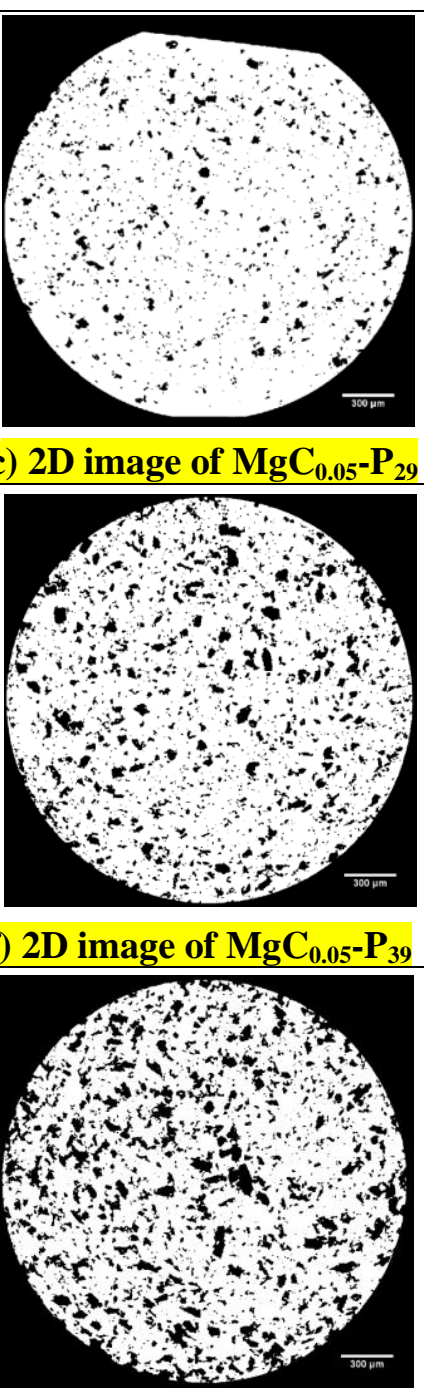

(i) 2D image of $\mathrm{MgC}_{0.05}-\mathrm{P}_{49}$
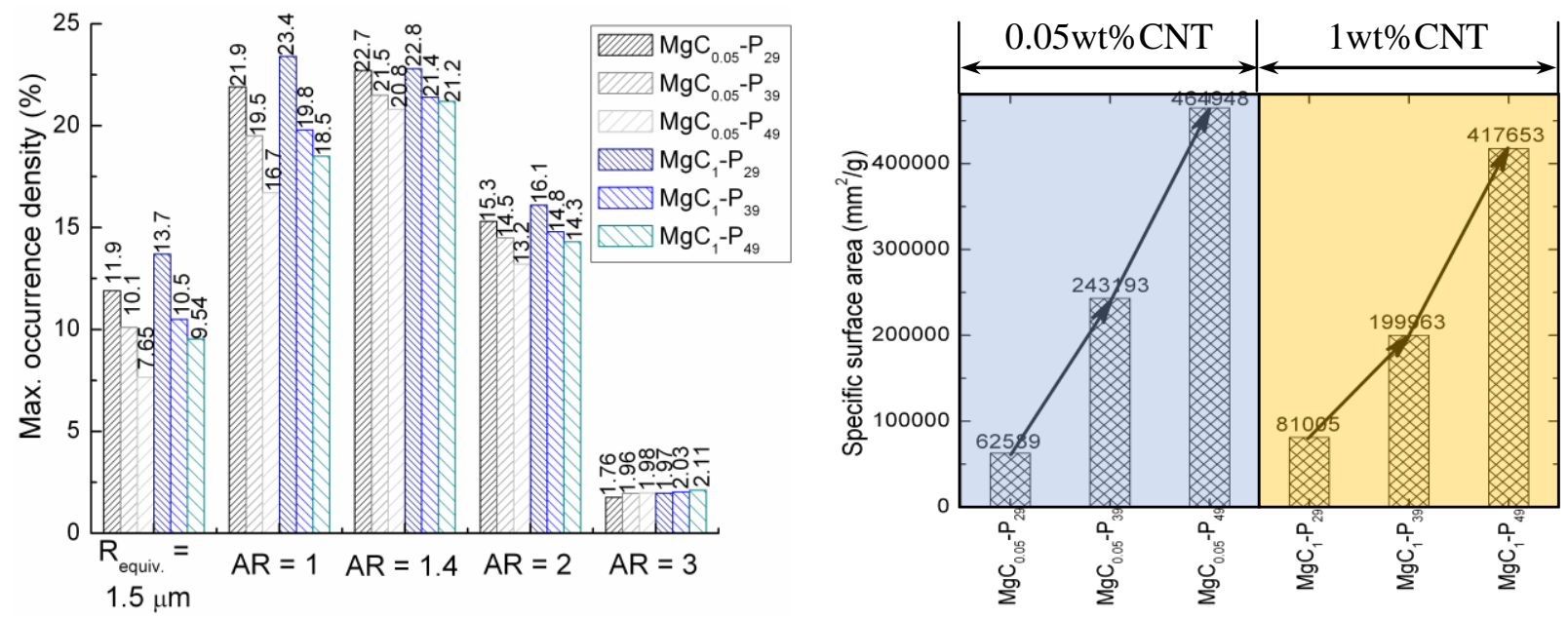